\title{
Performing Subcutaneous Injections: A Literature Review
}

\author{
Magdalena Annersten, RN, MNs, Ania Willman, RN, BEd, PhD
}

\begin{abstract}
Background: Persons using daily subcutaneous injections to administer medicine perform them in different ways and thereby increase the risk of skin complications related to the injection. It is often part of nurses' role to administer medicine and educate the patient in injection technique. Course literature in nursing education, commercial patient education pamphlets, and instructional leaflets do not give consistent advice regarding subcutaneous injection technique.

Aim: The aim of this review was to identify the scientific foundation for the technical performance of subcutaneous injections. The question to be answered was: How should a subcutaneous injection be administered to achieve the right dose in the right place with minimum complications?

Method: The review included a search in three databases, a screening process at abstract level, followed by a quality assessment of included articles. The quality assessment was done independently by two people and followed specific protocols.

Result: A total of 38 articles were assessed for quality and covered information on dose, location, and complications of subcutaneous injection. The assessed studies are heterogeneous in design and describe different aspects of the subcutaneous injection technique. Therefore, the scientific foundation for technical performance is weak. However, several studies indicate that the amount of subcutaneous fat and appropriate needle length are of high importance for the drug to reach the target tissue.

Conclusion: More research regarding effective subcutaneous injection technique needs to be done.
\end{abstract}

Worldviews on Evidence-Based Nursing 2005; 2(3):122-130. Copyright @2005 Sigma Theta Tau International

KEYWORDS administration of medication, diabetes, heparin, injection technique, insulin, insulin pen, lipohypertrophy, needles, subcutaneous injection, literature review, syringe

\section{INTRODUCTION}

$I^{n}$ n Sweden, approximately 200,000 injections are administered subcutaneously every day (Apoteket 2001). In Sweden, as in other countries, it is part of the nurse's role to administer medication and teach patients how to inject correctly. Nurses, as well as patients, perform subcutaneous injections in different ways. This increases the risk of skin lesion and complications related to the injections. Epi-

Magdalena Annersten, Öresund Diabetes Team AB, Lund, Sweden. Ania Willman, School of Health and Society, Malmö University, Malmö University Hospital, Sweden.

Address correspondence to Magdalena Annersten, RN, MNs, Öresund Diabetes Team AB, Ideon Science Park $\beta 2$, Scheelevägen 17, SE 22370 Lund, Sweden; oresund@diabetes.ideon.se

Submitted 25 May 2004; Accepted 22 December 2004

Copyright $(2005$ Sigma Theta Tau International

$1545-102 \times 1 / 05$ demiological studies have shown 30\% prevalence of lipohypertrophy in insulin-treated patients (Becton Dickinson 2000). It is therefore important that injection administration is based on scientific evidence of how best to perform this role. However, at present, it is difficult for nurses to incorporate best available evidence because literature used in nursing education, commercial patient information pamphlets, and instructional leaflets gives inconsistent advice regarding subcutaneous injection technique. These difficulties are not mitigated by compiled literature reviews, since the assessment process is not explicitly presented (e.g., Thow \& Home 1990; Beyea \& Nicoll 1996; Nicoll \& Beyea 1996; Strauss et al. 1999). Therefore, the aim of this study was to review, with a systematic approach, the scientific literature regarding the practical and technical performance of a subcutaneous injection. The specific question to be answered by the review was: How should a subcutaneous injection be administered to achieve the right dose in the right place with minimum complications? 


\section{METHOD}

Using a traditional evidence-based practice approach, the following steps were taken: asking answerable questions, accessing best information, appraising information for validity and relevance, and applying information in patient care (Swedish Council on Technology Assessment in Health Care [SBU] 1993). A subcutaneous injection includes several components. To identify these and to specify the search terms, Flemming's work (Flemming 1998) was used as a guide. By defining the situation, intervention, counter intervention, and outcome of the intervention, three outcomes emerged: dose, location, and complication.

Inclusion criteria for studies to be examined were

- published between the years 1966 and 2003 and written in English, German, Spanish, Swedish, or Danish;

- the population investigated needed to be humanadults or children;

- the equipment (i.e., syringes, needles, injection pens, etc.) used in the studies had to be in clinical use in Sweden from the 1980s and later; and

- the intervention should be an injection into the subcutaneous fat layer, or the activities around it such as preparation of the dose, cleaning of the skin, etc.

Studies on intramuscular or intravenous injections were excluded. The preferred outcome was either right dose, right location, or report on any complications (see Table 1). To build a foundation for practice recommendations, the assumption was that included studies should have used descriptive or controlled methods.

The literature search was performed using the databases Medline and CINAHL. It was assumed that both these databases would include studies reporting on the administration of medication. The pedagogy-focused database ERIC was also searched, as teaching the patients the selfinjection technique is an important role of nurses. To identify other potential sources of evidence, written documen-

\section{TABLE 1}

Inclusion criteria

\begin{tabular}{ll}
\hline YEAR & \multicolumn{1}{c}{ 1966-2003 } \\
\hline Languages & $\begin{array}{c}\text { English, German, Spanish, Swedish, } \\
\text { Danish } \\
\text { Adults and children }\end{array}$ \\
$\begin{array}{l}\text { Population } \\
\text { Injection equipment }\end{array}$ & $\begin{array}{l}\text { Used in Sweden from 1980 and later } \\
\text { Injection in the subcutaneous fat layer, or } \\
\text { dosage } \\
\text { Right dose, right location, report on } \\
\text { Cutcomplications } \\
\text { Controlled trials or descriptive studies }\end{array}$ \\
\hline
\end{tabular}

tation from two conferences held in Strasbourg in 1997 (Strauss 1998) and in Barcelona in 2000 (Becton Dickinson 2000) for researchers with a special interest in injection technique was read, and some of the participants were contacted via e-mail for further information and documentation.

\section{Literature Search}

The literature search in Medline (via PubMed) was conducted in December 2003, using the MeSH (medical subject headings) terms:

- "Injection, Subcutaneous"

- "Needles"

- "Insulin"

- "Heparin Low-Molecular Weight"

- "Nursing Evaluation Research"

- "Lipodystrophy"

- and the free text words "Injection Site" and "Subcutaneous Injection Complication"

The terms were used independently or in various combinations, using "AND." In the German search, the free text terms "Injektzion technik" AND "Diabetes" were used; in Spanish, the free text terms "Jeringa," "Inyeccion," "Diabetes Mellitus," "Enfermeria" were used. In the Danish search, the free text term used was "injektionsteknik," and the same term was used in the Swedish search.

The search in CINAHL was also conducted during December 2003, using subheadings:

- "Injection-Subcutaneous-Methods"

- "Heparin-Administration-and-Dosage"

- "Insulin-Administration-and-Dosage"

- "Injections"

- "Injection-Sites"

- "Injection-Subcutaneous-Adverse-Effects"

- "Syringes"

- "Lipodystrophy"

The search in the database ERIC, using the search term Subcutaneous injection, did not identify any abstracts that could address the research question.

The references from previous literature reviews on this subject were manually searched (Thow \& Home 1990; Beyea \& Nicoll 1996; Nicoll \& Beyea 1996; Strauss et al. 1999), and it was found that this search covered their included references.

A total of 102 abstracts were screened, using the inclusion criteria to select articles for further appraisal. From the 102 abstracts, 87 full-text articles were retrieved for closer screening; another 15 articles were received from European researchers. Criteria for this later screening included the following: whether the study had investigated right dose, 
right place, or complications; whether the injection studied had actually been subcutaneously placed and verified by CT scanning, ultrasound, or by lifting up a skin fold; and finally whether the problem studied was measurable with the method used. If there was no description of how the injection studied had been placed, and how this was controlled for in the study, the article was excluded. After excluding articles that did not meet this later criterion, 36 articles from Medline and CINAHL were included together with two from other researchers. Therefore, a total of 38 articles were critically appraised.

\section{Assessment}

The 38 full-text documents were assessed by two independent reviewers, using assessment sheets modified from available literature about critical appraisal (Greenhalgh 1997; Polit \& Hungler 1999; Willman \& Stoltz 2002). The assessment sheet included data on the inclusion and exclusion criteria, the number of study subjects, what outcome was investigated, how this was measured, and whether the method chosen was appropriate. Data on the procedure for randomization, group comparability, blinding process, duration, and follow-up was also assessed, together with the statistical analysis. The reviewers met to compare and discuss their responses to the assessments. The quality for each article was graded on a three-point scale where one point refers to high scientific quality, three points refers to low scientific quality, and two points to moderate. This is the grading system used by the SBU for systematic reviews (SBU 1993, 1997, 2000). The studies were divided into two groups: descriptive studies and controlled studies. No studies using a qualitative approach were identified.

The results of the assessment were integrated in evidence tables including the following information: name of the author, publishing year, country, method design, investigated population, intervention, outcome and quality level, a short summary of the author's own result, the length of the needle used, and proven subcutaneous position.

\section{FINDINGS}

The 38 articles assessed for quality reported on many different aspects of the subcutaneous injections. In the quality assessment, 8 studies scored one point, 23 scored two points, and 7 scored three points. The eight one-point scoring studies are briefly presented below alongside the 23 two-point scoring studies in Tables 2, 3, and 4. The studies are presented in three tables according to three different aspects of the research question: dose, location, or complications.

\section{How to Achieve the Right Dose}

Bell et al. (1991) investigated, in a descriptive study of 90 patients and 28 health care professionals, the accuracy of dosage, using industrial pre-mixed insulin compared to self-mixed insulin. At low doses, both patients and professionals showed greater accuracy with achieving the right dose with pre-mixed insulin than with self-mixed insulin. Jehle et al. (1999) assessed whether Neutral Protamine Hagedorn (NPH) and insulin were accurately re-suspended by 109 patients measuring the content of their own vials and cartridges. Mixing of insulin by a mechanical device showed that at least 20 cycles of tipping the vial are necessary before complete re-suspension is achieved. Insulin content in patients' own cartridges or vials ranged from 5 to $214 \%$ of $100 \mathrm{IU} / \mathrm{ml}$. The cartridge or vial was tipped and rolled more than 10 times by $9 \%$ of the patients. For all patients, there was a correlation between the absolute error of NPH insulin suspension and cycles of rolling and tipping the insulin $(r=0.23, p=<0.05)$.

TABLE 2

How to achieve the right dose

\begin{tabular}{|c|c|c|c|c|}
\hline AUTHOR/YEAR & CONTENT & SUBJECTS $(n)$ & $\begin{array}{c}\text { NEEDLE PLACEMENT } \\
\text { PROVED BY }\end{array}$ & $\begin{array}{l}\text { DESIGN/ } \\
\text { OUALITY }\end{array}$ \\
\hline $\begin{array}{l}\text { Bell et al. } \\
\quad(1991)\end{array}$ & Dose accuracy & $\begin{array}{l}118 \text { subjects } \\
\quad(1,080 \text { doses })\end{array}$ & No injection performed & $\begin{array}{l}\text { Descriptive } \\
\quad \text { PGC } 1\end{array}$ \\
\hline $\begin{array}{l}\text { Silva et al. } \\
\quad(1996)\end{array}$ & Dose accuracy & $\begin{array}{l}15 \text { caretakers of children } \\
\text { (540 doses) }\end{array}$ & No injection performed & $\begin{array}{l}\text { Descriptive } \\
\quad 2\end{array}$ \\
\hline Ltief \& Schwenk (1999) & Dose accuracy & $\begin{array}{l}32 \text { children and } 16 \text { parents } \\
\text { (144 doses) }\end{array}$ & No injection performed & Descriptive 2 \\
\hline Jehle et al. (1999) & Dose accuracy & 109 vials from 109 diabetes patients & No injection performed & Descriptive CT 1 \\
\hline Annersten \& Frid (2000) & $\begin{array}{l}\text { Drip after injection with } \\
\text { injection pen }\end{array}$ & 20 healthy volunteers (480 injections) & Lifted skin fold & Descriptive 2 \\
\hline
\end{tabular}

$\mathrm{PGC}=$ parallel group comparison; $\mathrm{CT}=$ controlled trial.

124 Third Quarter $2005 \bullet$ Worldviews on Evidence-Based Nursing 
Performing Subcutaneous Injections

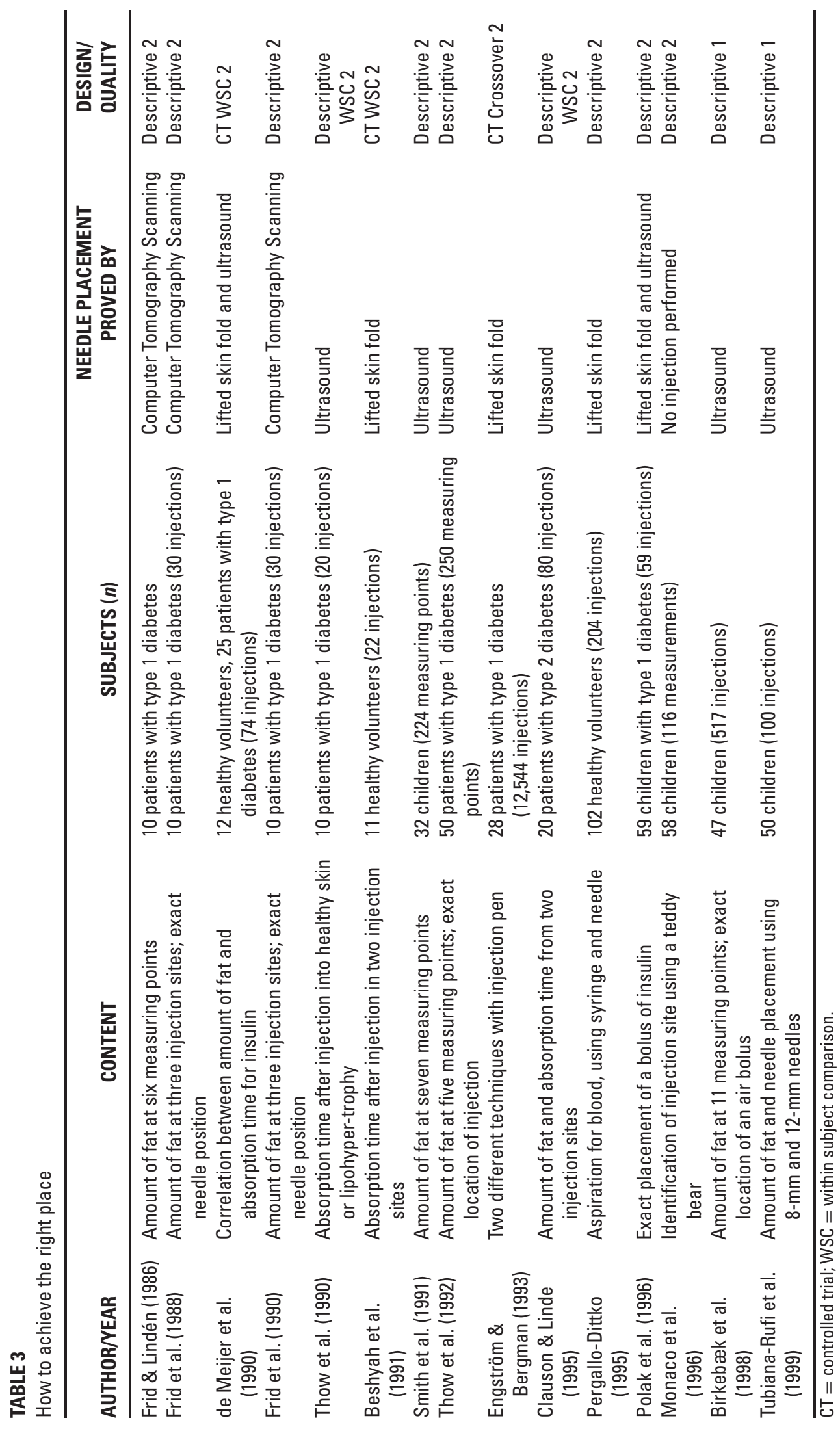




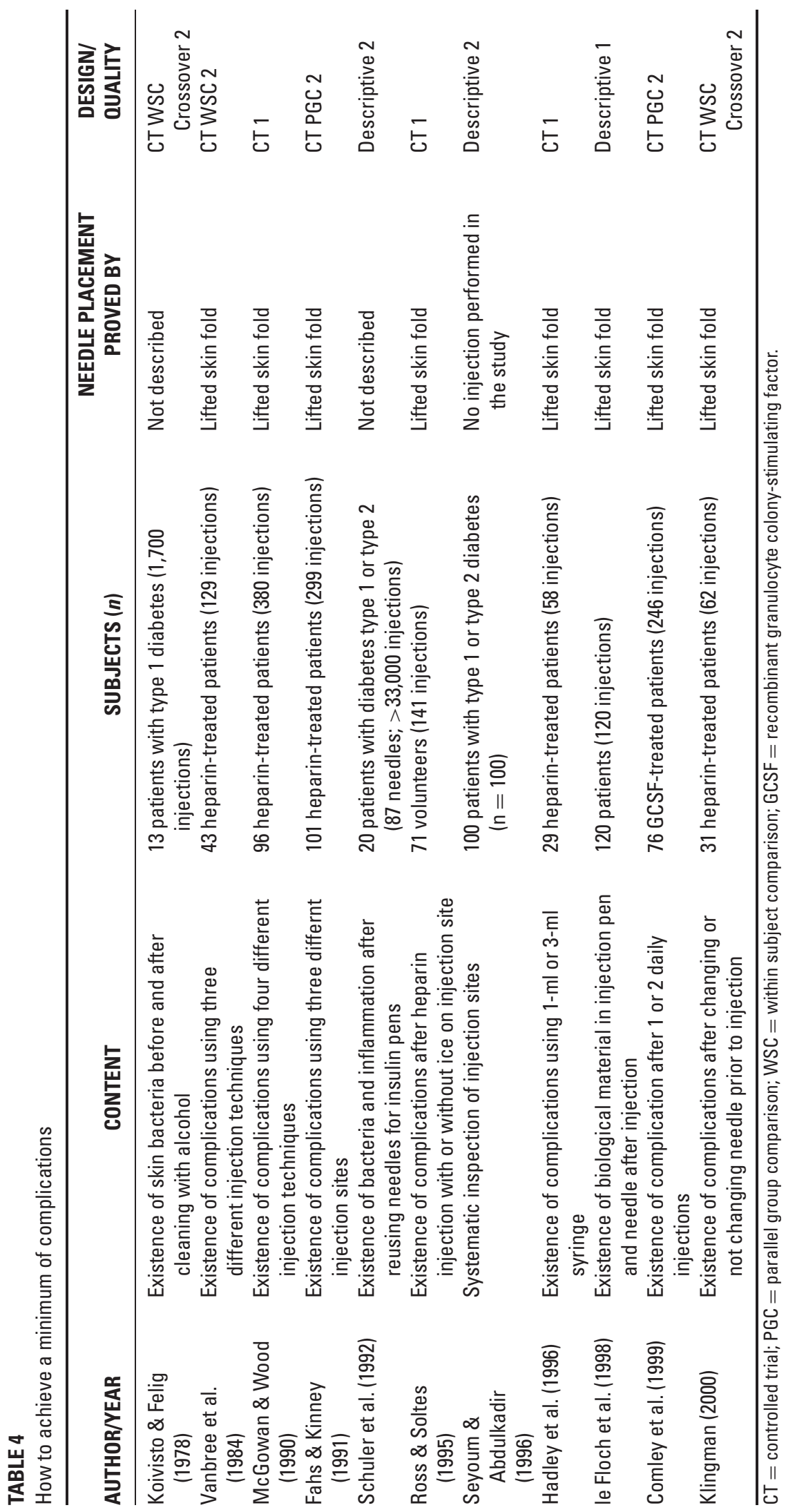




\section{How to Achieve the Right Place}

Birkebæk et al. (1998) in a descriptive study evaluated cutis/subcutis thickness on 47 children, at 11 measuring points at injection sites. Location of an air bolus injection with $8-\mathrm{mm}$ and $12-\mathrm{mm}$ needles was assessed by using ultrasound. The result showed that girls generally had more subcutaneous fat than boys and that compression of the skin reduced the distance from the surface to muscle fascia by $33 \%$. The air bolus injection was inappropriately placed by $19 \%$ of the children using an $8-\mathrm{mm}$ needle. Tubiana-Rufi et al. (1999) in a prospective crossover study of 50 children explored whether 8-mm needles could reduce the frequency of intra-muscular injections when compared with 12.7-mm needles. Using ultrasound, researchers assessed the localization of the needle tip on injection of insulin. The result showed that $88 \%$ of the children had $<12.7 \mathrm{~mm}$ and $40 \%$ had $<8$-mm subcutaneous fat at the injection sites. At the time of the study, the needles most commonly used were $8 \mathrm{~mm}$ or $12.7 \mathrm{~mm}$ in length. Of the 50 injections performed with a 12.7 -mm needle in a two-finger-pinch lifted skin fold, $86 \%$ were placed in the muscle instead of the fat layer. With an $8-\mathrm{mm}$ needle, $38 \%$ of the 50 injections were placed in the muscle instead of the subcutaneous fat layer.

\section{How to Achieve Minimum Complications}

McGowan and Wood (1990) in an experimental study compared the relationship between four different injection techniques and bruising after an injection with heparin. The injections were given to 96 patients, using a 16-mm needle. There was no statistical difference between the four injection techniques used and the existence of bruises. Ross and Soltes (1995) in a quasi-experimental study compared whether ice applied on the skin pre- and post-injection with heparin on 70 healthy volunteers had any impact on the existence of, and size of, haematoma. The result of 141 injections with a 16-mm needle in a lifted skin fold showed no significant difference in the incidence or size of hematoma. Hadley et al. (1996) assessed incidence and size of haematoma after heparin injection with a 1-ml syringe and a 3-ml syringe in a lifted skin fold in 29 patients $(n=$ 58 injections). The incidence of bruising did not differ significantly between 1-ml and 3-ml syringes, but the use of a 3-ml syringe resulted in significantly smaller bruises.

Le Floch et al. (1998) conducted a prospective study with 120 patients. A nurse injected insulin with the patient's own insulin pen and an 8-mm or a $12.7-\mathrm{mm}$ needle. A cytopathological examination was performed on the material obtained from the needles and found in the cartridge after the injection. Air bubbles were found in $45 \%$ of the cartridges. Biologic material was found in 30\% of the needles and in $58 \%$ of the cartridges, and in $25 \%$ of both needle and cartridge.
These 38 studies included here do investigate different aspects of the subcutaneous injection technique, but they differ in study design, subjects included, and outcomes measured. Therefore, it is difficult to formulate clear recommendations. From the literature reviewed here, there is no evidence to support general recommendations for the technical performance of the subcutaneous injection. Conclusions might be made from the findings - that the size of the injection needle should be adjusted to the amount of subcutaneous fat a person has. In practice, this amount can sometimes be difficult to estimate. Complications in connection with heparin injection seem to depend more on heparin itself rather than the injection technique used. The research evidence also seems to point toward individualizing care. However, to achieve this, the practitioner needs an explicit practice foundation so that she/he knows how individual changes should and can be made.

\section{DISCUSSION}

The result of this literature review reveals that there is little research evidence to support the formulation of recommendations regarding the performance of subcutaneous injection.

The fact that studies have been performed on many different aspects of subcutaneous injection reveals that this is an important clinical area for nurses and others. The most relevant approach to measuring effectiveness is a wellconducted randomized clinical trial. This design is difficult to perform on injection technique, since many of its components cannot (like choice of injection site), or should not (like dose accuracy), be blinded. To provide information regarding anatomical facts, such as fat depth, descriptive studies are relevant and indeed were included in this literature review. Case studies are informative regarding complications but are not a sufficient foundation for general conclusions and were therefore excluded. In the abstracts from Medline and CINAHL, several articles included 1- to 10-step instructions about how to perform an injection. These abstracts were excluded, since there is no convincing evidence that a certain technique is better than another just because it has been practiced for a long time. However, the frequent occurrence of step-by-step instructions reveals the need for further research, to build up a scientific foundation for such instructions.

Ideally after the search for studies has begun, the inclusion and exclusion criteria used should not be modified (SBU 1993). However, with regards to this particular review, it was soon revealed that many studies before 1980 were performed with injection tools no longer in use in Sweden. Therefore, studies published before 1980 were excluded from the result except for one that had studied skin 
bacteria, as alcohol swab is still in use (Koivisto \& Felig 1978).

The use of MeSH terms in Medline became cumbersome. The initial search turned out to include clinical trials regarding any medication intended for injection, giving a lot of pharmacological information but no information about which injection technique had been used. This is a weakness in the reporting of a new drug, as there is no information about whether the correct dose is given in the intended tissue. The abstracts from the chosen subheadings in CINAHL were surprisingly often medically oriented, referring to medical effects or side effects of different drugs, with little or no information on the injection technique or other nursing aspects.

Of the published studies, only a small number were performed on persons suffering from diabetes mellitus type 2 , in spite of the fact that these patients constitute the largest group receiving subcutaneous injections in Sweden and many other countries. Many of the excluded studies regarding absorption of drugs could not be included, as the authors did not explain how the injection had been performed and whether the injection had reached the intended fat tissue or not. Several studies on heparin injection had more than one dependent variable, which makes it hard to draw any conclusions. Previous literature reviews included studies covered by this search, but the authors did not explain how the selection of included articles had been carried out.

\section{Implications for research and practice}

- Habits and practices of people who inject medication subcutaneously need to be described further, including the existence of injection-related complications.

- Factors that influence patients' actual injection technique compared to nurses' recommendations need to be investigated.

- Differences in the rate of injection complications in people receiving injections from nurses/health care staff compared with people taking the injections themselves need to be explored.

- More studies should target diabetes type 2 patients, obese people, and elderly people, as these are the largest groups receiving insulin (and low-weightheparin) injections.

- Methods for estimation of subcutaneous fat tissue need to be evaluated to facilitate the choice of correct injection equipment and needle length.

- Studies on people with different skin colour could facilitate the development of methods to identify skin complications.

128 Third Quarter 2005• Worldviews on Evidence-Based Nursing
- Studies need to be done on the leakage of drugs at the injection site and the eventual clinical importance of drug leakage.

- Injections sites should have a sufficient amount of fat.

- Children and lean adults need short needles to avoid intra-muscular injection.

- Patients need instruction and follow-up when beginning self-injection therapy.

- Injection sites should be systematically inspected and routinely documented.

\section{Acknowledgments}

Becton Dickinson, United States, contributed with copying the articles. Elisabeth Pettersson, RN, has fully participated in the assessment process and the fruitful discussion.

\section{References}

Annersten M. \& Frid A. (2000). Insulin pens dribble from the tip of the needle. Practical Diabetes International, $17(4), 109-111$.

Apoteket (2001). Sales report on injection needles and syringes 2000. Stockholm: Swedish Pharmacy Chain.

Becton Dickinson (2000). S.I.T.E. 2000: Second Injection Technique Event. Barcelona: Becton Dickinson.

Bell D.S., Clements R.S., Perentesis G., Roddam R. \& Wagenknecht L. (1991). Dosage accuracy of self-mixed vs premixed insulin. Archives of Internal Medicine, 151(11), 2265-2269.

Beshyah S.A., Anyaoku V., Niththyananthan R., Sharp P. \& Johnston D.G. (1991). The effect of subcutaneous injection site absorption of human growth hormone: $\mathrm{Ab}$ domen versus thigh. Clinical Endocrinology (Oxf), 35(5), 409-412.

Beyea S. \& Nicoll L. (1996). Subcutaneous administration of heparin: An integrative review of the research. Worldviews on Evidence-Based Nursing presents the archives of The Online Journal of Knowledge Synthesis for Nursing, E3(1), 1-5. Retrieved February 10, 2005, from www.blackwellpublishing.com/wvn.

Birkebæk N.H., Johansen A. \& Solvig J. (1998). Cutis/subcutis thickness at insulin injection sites and localization of simulated insulin boluses in children with type 1 diabetes mellitus: Need for individualization of injection technique? Diabetic Medicine, 15(11), 965-971.

Clauson P.G. \& Linde B. (1995). Absorption of rapid-acting insulin in obese and nonobese NIDDM patients. Diabetes Care, 18(7), 986-991.

Comley A.L., DeMeyer E., Adams N., Edwards C., Gilman L.C., Good A., et al. (1999). Effect of subcutaneous granulocyte colony-stimulating factor injectate volume on 
drug efficacy, site complications, and client comfort. Oncology Nursing Forum, 26(1), 87-94.

de Meijer P.H., Lutterman J.A., van Lier H.J. \& van’t Laar A. (1990). The variability of the absorption of subcutaneously injected insulin: Effect on injection technique and relation with brittleness. Diabetic Medicine, 7(6), 499-505.

Engström L. \& Bergman A. (1993). A new injection technique for insulin treatment, simpler to use and as effective? Scandinavian Journal of Caring Sciences, 7(1), 57-59.

Fahs P.S. \& Kinney M.R. (1991). The abdomen, thigh, and arm as sites for subcutaneous sodium heparin injections. Nursing Research, 40(4), 204-207.

Flemming K. (1998). Asking answerable questions. Evidence Based Nursing, 1(2), 36-37.

Frid A., Gunnarsson R., Güntner P. \& Linde B. (1988). Effects of accidental intramuscular injection on insulin absorption in IDDM. Diabetes Care, 11(1), 4145.

Frid A. \& Lindén B. (1986). Where do lean diabetics inject their insulin? A study using computed tomography. British Medical Journal, 292(6536), 1638.

Frid A., Östman J. \& Linde B. (1990). Hypoglycemia risk during exercise after intramuscular injection of insulin in thigh in IDDM. Diabetes Care, 13(5), 473-477.

Greenhalgh T. (1997). How to read a paper. London: British Medical Journal Publishing Group.

Hadley S.A., Chang M. \& Rogers K. (1996). Effect of syringe size on bruising following subcutaneous heparin injection. American Journal of Critical Care, 5(4), 271276.

Jehle P., Micheler C., Jehle D., Breitig D. \& Boehm B.O. (1999). Inadequate suspension of neutral protamine Hagedorn (NPH) insulin in pens. Lancet, 354(9190), 1604-1607.

Klingman L. (2000). Effects of changing needles prior to administering heparin subcutaneously. Heart $\&$ Lung, 29(1), 70-75.

Koivisto V.A. \& Felig P. (1978). Is skin preparation necessary before insulin injection? Lancet, 1(8073), 10721075.

Le Floch J.P., Herbreteau C., Lange F. \& Perlemuter L. (1998). Biologic material in needles and cartridges after insulin injection with a pen in diabetic patients. Diabetes Care, 21(9), 1502-1504.

Ltief A. \& Schwenk W.F. (1999). Accuracy of pen injectors versus insulin syringes in children with type 1 diabetes. Diabetes Care, 22(1), 137-140.

McGowan S. \& Wood A. (1990). Administering heparin subcutaneously: An evaluation of techniques used and bruising at the injection site. Australian Journal of Advanced Nursing, 7(2) 30-39.
Monaco L., Geffken G. \& Silverstein J.H. (1996). Accuracy of injection site identification among children with insulin dependent diabetes mellitus: A comparison of traditional and new visual aids. Clinical Pediatrics, 35(4), 191-197.

Nicoll L. \& Beyea S. (1996). Subcutaneous administration of insulin in adults: An integrative review of the research. Worldviews on Evidence-Based Nursing presents the archives of The Online Journal of Knowledge Synthesis for Nursing, E3(1), 19-24. Retrieved February 10, 2005, from www.blackwellpublishing.com/wvn.

Pergallo-Dittko V. (1995). Aspiration of the subcutaneous insulin injection: Clinical evaluation of needle size and amount of subcutaneous fat. The Diabetes Educator, 21(4), 291-296.

Polak M., Beregszaszi M., Belarbi N., Benali K., Hassan M., Czernichow P. \& Tubiana-Rufi N. (1996). Subcutaneous or intramuscular injections of insulin in children. Are we injecting where we think we are? Diabetes Care, 19(12), 1434-1436.

Polit D.F. \& Hungler B.P. (1999). Nursing research principles and methods. Philadelphia: Lippincott.

Ross S. \& Soltes D. (1995). Heparin and haematoma: Does ice make a difference? Journal of Advanced Nursing, 21(3), 434-439.

SBU (Swedish Council on Technology Assessment in Health Care). (1993). Literature searching and evidence interpretation for assessing health care practices. Retrieved February 10, 2005, from www.sbu.se/www/index.asp.

SBU (Swedish Council on Technology Assessment in Health Care). (1997). Behandling med neuroleptika. (Treatment with neuroleptics). Report No. 113 [in Swedish]. Stockholm: Author.

SBU (Swedish Council on Technology Assessment in Health Care). (2000). Behandling av astma och KOL. En systematisk kunskapssammanställning. (Treating asthma and COPD. A systematic review), Vol. 115 [in Swedish]. Stockholm: Author.

Schuler G., Pelz K. \& Kerp L. (1992). Is the reuse of needles for insulin injection systems associated with a higher risk of cutaneous complications? Diabetes Research Clinical Practice, 16(3), 209-212.

Seyoum B. \& Abdulkadir J. (1996). Systemic inspection of insulin injection sites for local complications related to incorrect injection technique. Trop Doct, 26(4), 159161.

Silva S.R., Clark L., Goodman S.N. \& Plotnick L.P. (1996). Can caretakers of children with IDDM accurately measure small insulin doses and dose changes? Diabetes Care, 19(1), 56-59.

Smith C.P., Sargent M.A., Wilson B.P. \& Price D.A. (1991). Subcutaneous or intramuscular insulin injections. Archives of Disease in Childhood, 66(7), 879-882.

Worldviews on Evidence-Based Nursing • Third Quarter 2005129 
Strauss K. (Ed.) (1998). Insulin injection techniques. Report from the First International Insulin Injection Technique Workshop, Strasbourg, France, June 1997. Practical Diabetes International, 15(6), Special Report.

Strauss K., Hannet I., McGonigle J., Parkes J.L., Ginsberg B., Jamal R. \& Frid A. (1999). Ultra-short (5 mm) insulin needles: Trial results and clinical recommendations. Practical Diabetes International, 16(17), 218221.

Thow J.C., Coulthard A. \& Home P.D. (1992). Insulin injection site tissue depths and localization of a simulated insulin bolus using a novel air contrast ultrasonographic technique in insulin treated diabetic subjects. Diabetic Medicine, 9(10), 915-920.

Thow J. \& Home P. (1990). Insulin injection technique. British Medical Journal, 301(6742), 3-4.
Thow J.C., Johnson A.B., Marsden S., Taylor R. \& Home P.D. (1990). Morphology of palpably abnormal injection sites and effects on absorption on isophane (NPH) insulin. Diabetic Medicine, 7(9), 795-799.

Tubiana-Rufi N., Belarbi N., Du Pasquier-Fediaevsky L., Polak M., Kakou B., Leridon L., et al. (1999). Short needles $(8 \mathrm{~mm})$ reduce the risk of intramuscular injections in children with type 1 diabetes. Diabetes Care, 22(10), 1621-1625.

Vanbree N.S., Hollerbach A.D. \& Brooks G.P. (1984). Clinical evaluation of three techniques for administering lowdose heparin. Nursing Research, 33(1), 15-19.

Willman A. \& Stoltz P. (2002). Evidensbaserad omvårdnaden bro mellan forskning och kliniska verksamhet. (Evidence based nursing-A bridge between research and clinical work.) Lund: Studentlitteratur [in Swedish]. 